\title{
Improvement of barrier and mechanical properties of whey protein isolate based food packaging films by incorporation of zein nanoparticles as a novel bionanocomposite
}

\author{
Pelin Oymaci a, Sacide Alsoy Altinkaya ${ }^{\mathrm{b}, *}$ \\ ${ }^{a}$ Department of Material Science and Engineering, Izmir Institute of Technology, Gulbahce Campus, 35430 Urla, Izmir, Turkey \\ ${ }^{\mathrm{b}}$ Department of Chemical Engineering, Izmir Institute of Technology, Gulbahce Campus, 35430 Urla, Izmir, Turkey
}

\section{A R T I C L E I N F O}

\section{Article history:}

Received 6 April 2015

Received in revised form

11 August 2015

Accepted 31 August 2015

Available online 4 September 2015

\section{Keywords:}

Whey protein isolate

Zein nanoparticle

Mechanical properties

Water vapor barrier properties

Free volume

Hydrophilicity

\begin{abstract}
A B S T R A C T
In this study, whey protein isolate (WPI) based bio-nanocomposite films embedded with zein nanoparticles (ZNP) were prepared by solution casting. Nanoparticles were coated with sodium caseinate to obtain a uniform distribution in the films. The mechanical, water vapor barrier, surface wetting, morphological and viscoelastic properties of the films were investigated. The addition of ZNP significantly improved the water vapor barrier and mechanical properties of the WPI without adversely affecting the elongation of the films. Dynamical mechanical analysis and contact angle measurements revealed that upon addition of the nanoparticles, the fractional free volume and hydrophilicity of the WPI films decreased. Sodium caseinate containing both hydrophilic and hydrophobic groups created an efficient interface between the hydrophobic ZNP and hydrophilic WPI matrix, allowing for a homogeneous distribution of nanoparticles even at very high loading levels as evidenced by the scanning electron microscope (SEM) and atomic force microscopy (AFM) images. The WPI/ZNP nanocomposite films can potentially become effective food packaging materials.
\end{abstract}

() 2015 Elsevier Ltd. All rights reserved.

\section{Introduction}

Most of the food packaging materials produced from nondegradable synthetic polymers represent a serious global environmental problem. In addition, the dependency on fossil resources limits the sustainability of food packaging production. As an alternative to plastic films, biopolymer-based packaging materials, which originated from naturally renewable resources such as polysaccharides, proteins, and lipids, have been recently of interest (Wihodo \& Moraru, 2013). The well-known application of biodegradable polymers in food packaging is as edible films which are used for individual coating of small food products or placed within the food. Biopolymer films can also improve the quality of food products and act as efficient carrier agent for incorporating various additives including antimicrobials, antioxidants, coloring agents, and other nutrients (Wihodo \& Moraru, 2013).

Economic production of bio-based food packaging materials requires the use of materials abundant in nature. Whey protein

\footnotetext{
* Corresponding author. Tel.: +90 2327506658; fax: +90 2327506645.

E-mail address: sacidealsoy@iyte.edu.tr (S.A. Altinkaya).
}

isolate (WPI) is one of the abundant proteins isolated from milk as a by-product of the manufacture process of cheese or casein. Compared to petroleum based synthetic films, WPI has desirable film forming and excellent gas barrier properties (Brindle \& Krochta, 2008; Fairley, Monahan, German, \& Krochta, 1996; Fang, Tung, Britt, Yada, \& Dalgleish, 2002; Gounga, Xu, \& Wang, 2007; Hong \& Krochta, 2003; Khwaldia, Perez, Banon, Desobry, \& Hardy, 2004; Mchugh, Aujard, \& Krochta, 1994; Mchugh \& Krochta, 1994; Min, Janjarasskul, \& Krochta, 2009; Perez-Gago, Serra, Alonso, Mateos, \& del Rio, 2005; Sothornvit \& Krochta, 2000). However, the application of WPI in food packaging is limited by the low tensile strength, intrinsic stiffness and poor moisture barrier properties of WPI. Various methods proposed to overcome inherent shortcomings of WPI based food packaging materials have been reviewed by Wihodo and Moraru (2013). The most commonly used approaches are blending with other biodegradable polymers, lipids, coating and lamination, plasticization, $\mathrm{pH}$ alteration and cross-linking by heat, chemicals, enzymes or irradiation. Recent works have explored the use of nanocomposites to improve the barrier and mechanical properties of WPI films. Sothornvit, Rhim, and Hong (2009) prepared WPI based nanocomposite films by blending the polymer with three different types of nanoclays at $5 \%$ 
level: Cloisite $\mathrm{Na}^{+}$, Cloisite 20A and Cloisite 30B. The nanoclay addition decreased the water vapor permeabilities, however, no significant improvement in mechanical properties was observed. In the following study of the same group, Cloisite 30B content in the films was changed from 5\% (wt.) to 20\% (Sothornvit, Hong, An, and Rhim (2010)). Although water vapor permeabilities decreased, mechanical strengths of all nanocomposite films were found lower than the plain WPI film. Wakai and Almenar (2015) observed slight increase in the tensile strength and significant decrease in the elongation at break values by loading 5 wt. \% unmodified $\mathrm{Na}^{+}$montmorillonite into WPI films. In the work of Zolfi, Khodaiyan, Mousavi, and Hashemi (2014) montmorillonite was added into a blend of WPI and kefiran. The tensile strength and Young modulus values increased significantly while elongation at break values and water vapor permeability of the films decreased with the increased clay content. Azevedo et al. (2015) observed an increase not only in tensile strength and elastic modulus but also in elongation at break values by adding $3 \%$ Cloisite $\mathrm{Na}^{+}$into WPI films. Zhou, Wang, and Gunasekaran (2009) reported that small amounts of $\mathrm{TiO}_{2}(<1 \%)$ addition significantly improved the tensile properties of WPI film, on the other hand had a negative effect on the moisture barrier properties. Kadam et al. (2013) coated $\mathrm{TiO}_{2}$ nanoparticles with a layer of silica and applied sonication to the film forming solution prior to casting to prevent aggregation of the particles. Combination of sonication and silica coating contributed to enhancing tensile stress at break and Young modulus values, however, this strategy did not alter the moisture barrier properties and caused $50 \%$ reduction in elongation of the films. $\mathrm{TiO}_{2}$ nanoparticle addition into WPI kefiran blend films slightly improved water vapor barrier but deteriorated the tensile properties of the films (Zolfi et al., 2014). The review of literature studies indicated that although the inorganic nanoparticles added into the WPI matrix improved several film properties, the mechanical and barrier properties remained at insufficient levels. This is mainly due to high agglomeration tendency of these nanoparticles caused by at least one order of magnitude difference between surface free energies of inorganic nanoparticles and polymers (Kingery, Bowen, \& Uhlmann, 1960). Compatibility between the polymer and particles can be improved by modifying the nanoparticles with organophilic surfactants. However, FDA approval of compatibilizers is required which significantly narrows the choice of these agents. Another drawback of using nano-sized clay or $\mathrm{TiO}_{2}$ in food packaging films is the lack of toxicology data and unknown allowable limits for migration of these nanoparticles into food. Slight improvement in the moisture barrier properties of the WPI films is not only due to inhomogeneous distribution but also because of the hydrophilic nature of both clay and $\mathrm{TiO}_{2}$ nanoparticles. These considerations led to the conclusion that new nanocomposite film formulations are needed to overcome the drawbacks observed in previous studies.

In this study, we proposed to use zein nanoparticles for preparing WPI nanocomposites. Zein is generally recognized as a safe (GRAS) biomaterial and has promising properties such as low toxicity, biodegradability and biocompatibility. Its high hydrophobicity makes it ideal for improving poor water vapor permeability of the WPI films. On the other hand, the challenge in benefiting from this unique property is to achieve homogeneous distribution of zein in the film matrix. We overcame this challenge by synthesizing the ZNP in the presence of sodium caseinate which is also classified in GRAS class (Li et al., 2013). Sodium caseinate is an amphiphilic milk protein; its hydrophobic groups adsorb on the ZNP, while hydrophilic portions provide homogeneous dispersion of the nanoparticle in the hydrophilic WPI matrix. In the manuscript, we characterized the distribution of the nanoparticles, and the structural changes in the WPI films caused by nanoparticle addition, and investigated the effect of these changes on the mechanical and barrier properties of WPI films. To the best of our knowledge, this is the first study which proposes the incorporation of ZNP in WPI films to enable the use of WPI as self-standing films rather than as edible film coatings.

\section{Materials and methods}

\subsection{Materials}

Whey protein isolate BiPRO and sodium caseinate were supplied by Davisco Foods and American Casein Company, respectively. Corn zein from maize and sodium hydroxide were purchased from Sigma-Aldrich Chemical. Glycerol and acetic acid were used from Panreac. Bacteriological peptone was obtained from Oxoid. Deionized water was used for all preparations.

\subsection{Preparation of nanoparticles}

Water soluble zein nanoparticles (ZNP) were prepared according to the procedure reported in the literature (Li et al., 2013). Zein $(0.5 \mathrm{~g})$ was dissolved in 80:20 (v/v) ethanol/water solvent mixture. Sodium caseinate $(1 \% \mathrm{w} / \mathrm{v})$ was also dissolved in $250 \mathrm{ml}$ water and poured into zein solution in a second under continuous stirring (1000 rpm). Ethanol was removed by rotary evaporator (Heidolph) and resultant mixture was then centrifuged at $4000 \mathrm{rpm}$ for $10 \mathrm{~min}$ to separate large aggregates in mixture prior to freeze-drying. Powdered ZNP were stored at $4{ }^{\circ} \mathrm{C}$ until used. ZNP were redispersed in water before added into WPI solution.

\subsection{Preparation of zein nanoparticle/whey protein isolate (ZNP/ WPI) nanocomposite films}

WPI (0.5 g) was dissolved in water to prepare $7 \%(\mathrm{w} / \mathrm{v})$ solution with magnetic stirrer in natural $\mathrm{pH}$ 7. Glycerol was then added to WPI solution as plasticizer (60\%, w/w of WPI) and solution was heated at $90{ }^{\circ} \mathrm{C}$ for $30 \mathrm{~min}$ in a water bath to denature the protein. ZNP were added at ratios of $0.2,0.4,0.8$ and $1.2(\mathrm{w} / \mathrm{w}$ of WPI) and re-dispersed in deionized water before adding to WPI solution. The nanoparticles were added slowly under rapid stirring and mixed over night to achieve good dispersion in protein solution. The film forming solutions were then cast onto polypropylene substrate $(8 \mathrm{~cm} \times 8 \mathrm{~cm})$ and dried at $25^{\circ} \mathrm{C}$ and $40 \pm 1 \% \mathrm{RH}$ for $24 \mathrm{~h}$ in an environmental chamber (Angelantoni Industrie, Italy, Challenge Series, model number: $\mathrm{CH} 250$ ). The films were easily peeled and stored at room temperature.

\subsection{Characterization of the nanoparticles and nanocomposite films}

\subsubsection{Dynamic light scattering (DLS)}

The particle size, particle size distribution and zeta potential of the nanoparticles were measured with dynamic light scattering (Malvern Instruments, Zetasizer Nano ZS). All measurements were performed in triplicate.

\subsubsection{Scanning electron microscope (SEM)}

SEM (FEI, Quanta250 FEG) was used to study the morphology of the nanoparticles and the cross sections of the films. Measurements were performed for pure WPI film and the film loaded with highest nanoparticle concentration to observe the dispersion and structural changes within the matrix. Specimens were prepared by fracturing films with liquid nitrogen and mounted on a double stick carbon tape to stand in upright position and coated with gold. To observe the morphology of the nanoparticles, $3 \mu \mathrm{l}$ droplet of diluted nanoparticle suspension was dried on the double stick carbon tape 
and then coated with gold. All samples were examined using an accelerating beam at a voltage of $5 \mathrm{kV}$.

\subsubsection{Atomic force microscopy (AFM)}

AFM analysis (Digital Instruments, MMSPM Nanoscope IV) was used to visualize the dispersed nanoparticles in WPI matrix. Film forming solutions were diluted to reduce the roughness of the films. $10 \mu \mathrm{l}$ of droplet was deposited on clean silicon wafer surface to dry and take image of the surface. The microscope was operated in tapping mode for all samples. AFM images with scan sizes of $10 \times 10,5 \times 5$ and $1 \times 1 \mu \mathrm{m}$ were acquired.

\subsubsection{Contact angle measurement}

The wettability of the films was determined with contact angle measurements performed in static mode using optical tensiometer (KSV, Attension Theta). A droplet of deionized water $(6 \mu \mathrm{l})$ was deposited onto different parts of the film surface and images were recorded in trigger mode. Each measurement was evaluated by taking one frame per second for $5 \mathrm{~min}$. Wettability properties were analyzed by evaluating the change in droplet volume with time.

\subsubsection{Viscoelastic properties of the films}

Viscoelastic properties of the films were measured with dynamic mechanical analysis (DMA) (TA Instruments, DMAQ800). Film strips were cut in $35 \mathrm{~mm}$ length and $5 \mathrm{~mm}$ width; mounted on tension film clamps and coated with hydrophobic grease. Measurements were performed in temperature ramp mode from $-60{ }^{\circ} \mathrm{C}$ to $25{ }^{\circ} \mathrm{C}$ with a heating rate of $3{ }^{\circ} \mathrm{C} / \mathrm{min}$ at $10 \mathrm{~Hz}$. Storage modulus and loss modulus curves were recorded with increasing temperature.

\subsubsection{Mechanical properties of the films}

The preparations of film specimens and measurements were done according to ASTM D-882-02 standard (ASTM., 2002). Texture analyzer (Texture Technologies, TA.XTPlus) equipped with $5 \mathrm{kgf}$ load cell was used in tensile mode to measure maximum tensile strength, percentage elongation at break and elastic modulus (Young's modulus) of the films from stress-strain curve. Sample films were conditioned at $50 \% \mathrm{RH}$ and $23{ }^{\circ} \mathrm{C}$ for $48 \mathrm{~h}$ before measurements. Film strips $5 \mathrm{~mm}$ in width were mounted on cardboard grips with initial grip separation of $50 \mathrm{~mm}$ and test speed was set to $25 \mathrm{~mm} / \mathrm{min}$. Tensile strength (TS) was calculated by dividing maximum load that the film could withstand by initial cross sectional area of the strip. Percent elongation at break (E) was determined as the strain at the fracture point which corresponds to the ratio of the change of length of the specimen to initial length. Elastic modulus (EM) was calculated from the slope of linear region in stress-strain curve. Measurements were performed at least in seven replicates for each film and the average of five results was reported.

\subsubsection{Water vapor permeability (WVP) of the films}

Water vapor permeability of the films (Mocon, Permatran-W 3/ 33 Plus) was measured in accordance with ASTM F 1249-90 standard (ASTM., 1995) at $24{ }^{\circ} \mathrm{C}$ and $25 \pm 1 \% \mathrm{RH}$. The area of the samples was fixed to $5 \mathrm{~cm}^{2}$ and specimens were sealed into the test cell by hydrophobic grease to prevent air entrance. For each film, four samples were analyzed and data were recorded as water vapor transmission rate (WVTR) in $\mathrm{g} / \mathrm{m}^{2}$ day unit. The WVP results (g.mm/ $\mathrm{m}^{2}$.h.kPa) were calculated using Equations (1) and (2):

$P_{w}=S\left(R_{1}-R_{2}\right)$
$\mathrm{WVP}=\frac{\mathrm{WVTR}}{\mathrm{P}_{\mathrm{w}}} \mathrm{L}_{\mathrm{film}}$

where $P_{w}$ is the partial pressure gradient of water vapor across the specimen $(\mathrm{kPa}) ; \mathrm{S}$ is the water vapor pressure at test temperature $(\mathrm{kPa}) ; \mathrm{R}_{1}$ is the set relative humidity at outer chamber of the cell $\left(R_{1}=0.25\right.$ for $\left.25 \% R H\right) ; R_{2}$ is the relative humidity of dry $N_{2}$ at inner chamber of the cell and $\mathrm{L}_{\text {film }}$ is the average thickness of the specimen $(\mathrm{mm})$. Thickness of the films was measured with a digital micrometer (Mitutoyo, 293-821) at five random points and mean values were used in the calculation.

\section{Results and discussion}

\subsection{Characterization of nanoparticles}

ZNP showed monodisperse size distribution as illustrated in Fig. 1 with polydispersity index smaller than $0.5(\mathrm{PDI}=0.14 \pm 0.003$ ). The mean size of the nanoparticles based on number weighted distributions was determined as $76.9 \pm 0.5 \mathrm{~nm}$. The zeta potential of the ZNP was found $-40.9 \mathrm{mV}$, which confirms the formation of stable dispersion, since a zeta potential of greater than $\pm 30 \mathrm{mV}$ is considered sufficient to maintain electrostatic repulsion among the particles, hence, to stabilize the particles (Riddick, 1968). Individual spherical ZNP were observed in SEM images although local aggregates were also encountered (Fig. 2). The particle sizes measured at different points in the image varied between 70 and $160 \mathrm{~nm}$ which was in agreement with the range obtained by DLS measurements.

\subsection{Characterization of the films}

\subsubsection{Morphological properties}

The cross sectional SEM images of the plain WPI and ZNP/WPI films can be seen in Fig. 3. A smooth, nonporous and homogeneous structure was observed in pure WPI films while individually scattered nanoparticles were detected in the matrix of ZNP/WPI films and no aggregates were encountered. The cross sections of the films were prepared by fracturing the films using liquid nitrogen which prevented any deformation at the interface, allowing for easy visualization of the nanoparticles. The small holes in the images were the traces of nanoparticles that remained on the opposite side of the film during fracturing.

AFM analysis was also applied to better understand the microstructure of the films. Fig. 4 shows globular microstructure of the pure WPI as reported previously in the literature (Ikeda \& Morris, 2002). The local aggregations in the pure WPI may be a result of the heat denaturation of proteins. Small differences between the phases could be attributed to the mixed composition of WPI itself due to the presence of more than one type of protein. Homogeneous distribution of ZNP was also observed in the ZNP loaded WPI films as shown in Fig. 5. The nanoparticles were individually scattered and phase differences between WPI matrix and ZNP was clearly distinguishable.

\subsubsection{Contact angle measurement}

Surface wetting property is a good indicator of the tendency of the films to absorb moisture or water, hence, can be used for evaluating water barrier properties of the films. Hydrophobicity of a surface is typically determined by measuring the contact angle of a water droplet on the film surface and in general, initial contact angles are reported. On the other hand, the contact angle is not time-independent, and can change within seconds or minutes due to swelling of the film, the change in liquid composition or evaporation of the liquid (Karbowiak, Debeaufort, \& Voilley, 2006; 


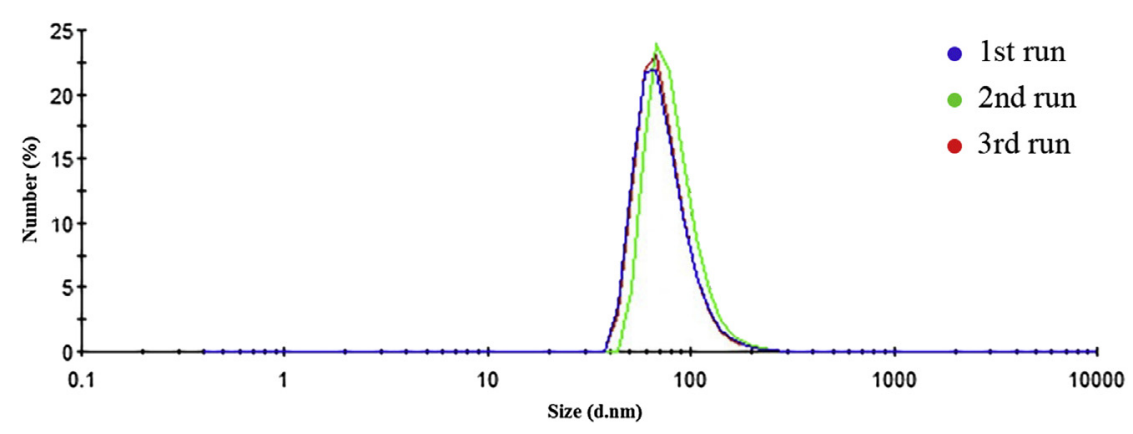

Fig. 1. Size distribution of ZNP by number.

Kokoszka, Debeaufort, Lenart, \& Voilley, 2010). In this case, initial contact angle values do not accurately represent the hydrophilic/ hydrophobic nature of the surface. To better evaluate the wetting characteristics of the films, we estimated the rate of absorption of water $\left(\dot{\mathrm{m}}_{\mathrm{abs}}\right)$ into the film by calculating the change in drop volume with time using Equation (3). Evaporation of water during the measurement was taken into account by considering the change in the volume of water dropped onto the impermeable aluminum foil.

$\dot{\mathrm{m}}_{\mathrm{Abs}}=\rho\left[\frac{\mathrm{dV}_{\mathrm{droplet}}}{\mathrm{dt}}-\frac{\mathrm{dV}_{\mathrm{ev}}}{\mathrm{dt}}\right]$

In this equation, $\rho$ represents the density of water and $d V_{e v}$ and $d V_{\text {Droplet }}$ correspond to the change in the droplet volume on the aluminum foil and WPI films, respectively. The absorption rates of water into pure WPI film and ZNP/WPI nanocomposite film were determined as $0.029 \mathrm{mg} / \mathrm{s}$ and $0.006 \mathrm{mg} / \mathrm{s}$, respectively. Compared to pure WPI films, the rate of water absorption into the ZNP/WPI nanocomposite film decreased significantly due to hydrophobic nature of zein.

\subsubsection{Viscoelastic properties of the films}

The changes in viscoelastic properties of the WPI films with nanoparticle loading were observed with dynamic mechanical analysis (DMA). The effects of temperature on storage ( $\left.E^{\prime}\right)$ and loss $\left(E^{\prime \prime}\right)$ modulus of the films are shown in Fig. 6. Over the entire temperature range, both $\mathrm{E}^{\prime}$ and $\mathrm{E}^{\prime \prime}$ of zein loaded films were higher than those of WPI films. This can be attributed to the reduced segmental mobility of the chains of WPI in the nanocomposite film. The relaxed rubber modulus of the WPI film increased and transition region broadened with nanoparticle addition. According to Ferry (1980), this behavior is observed since particles are bridged to each other by polymer chains and act as multiple cross-links as well
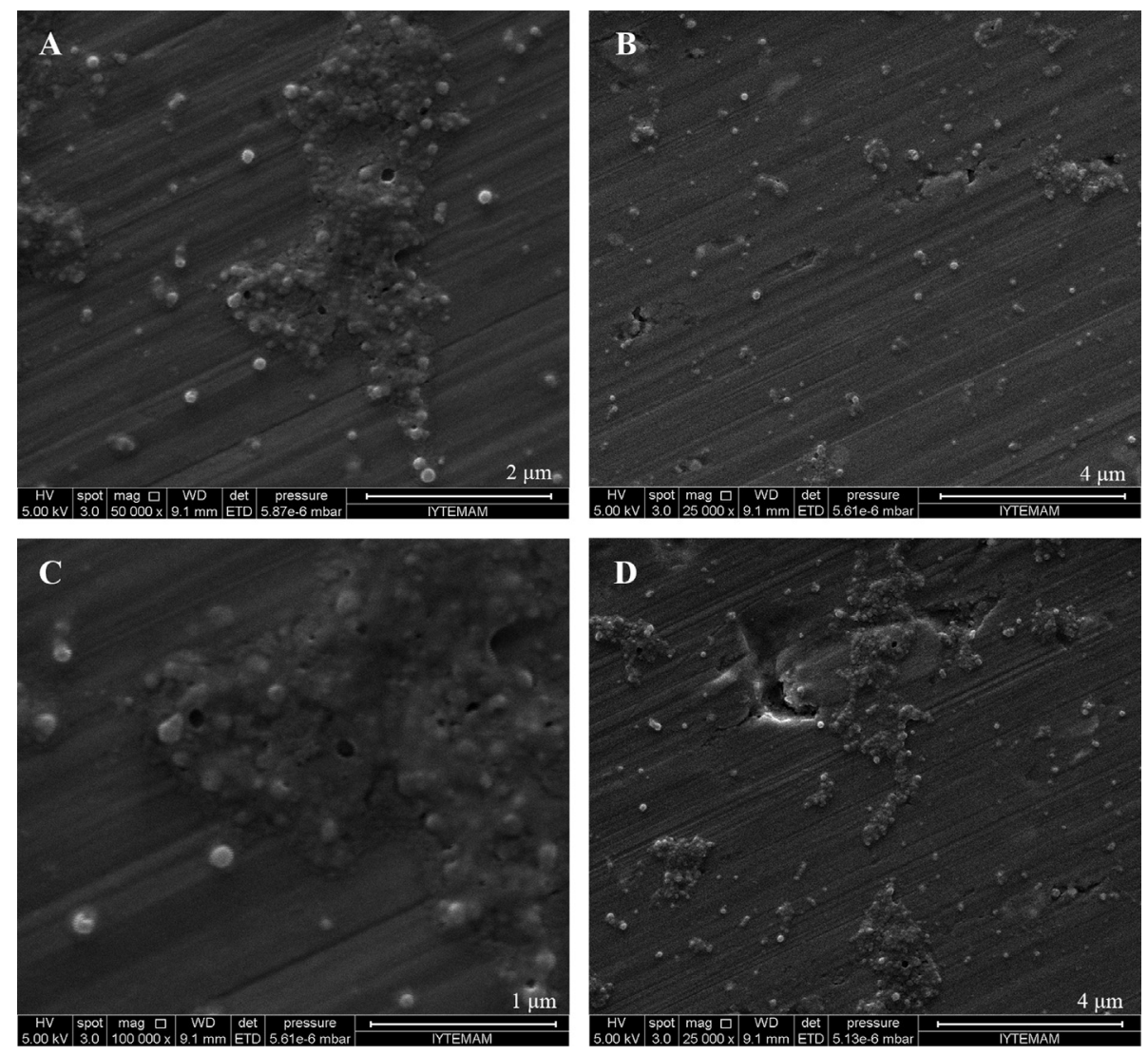

Fig. 2. SEM images of ZNP (a: $50000 \times$, b: $25000 \times$, c: $100000 \times$, d: $25000 \times$ ). 

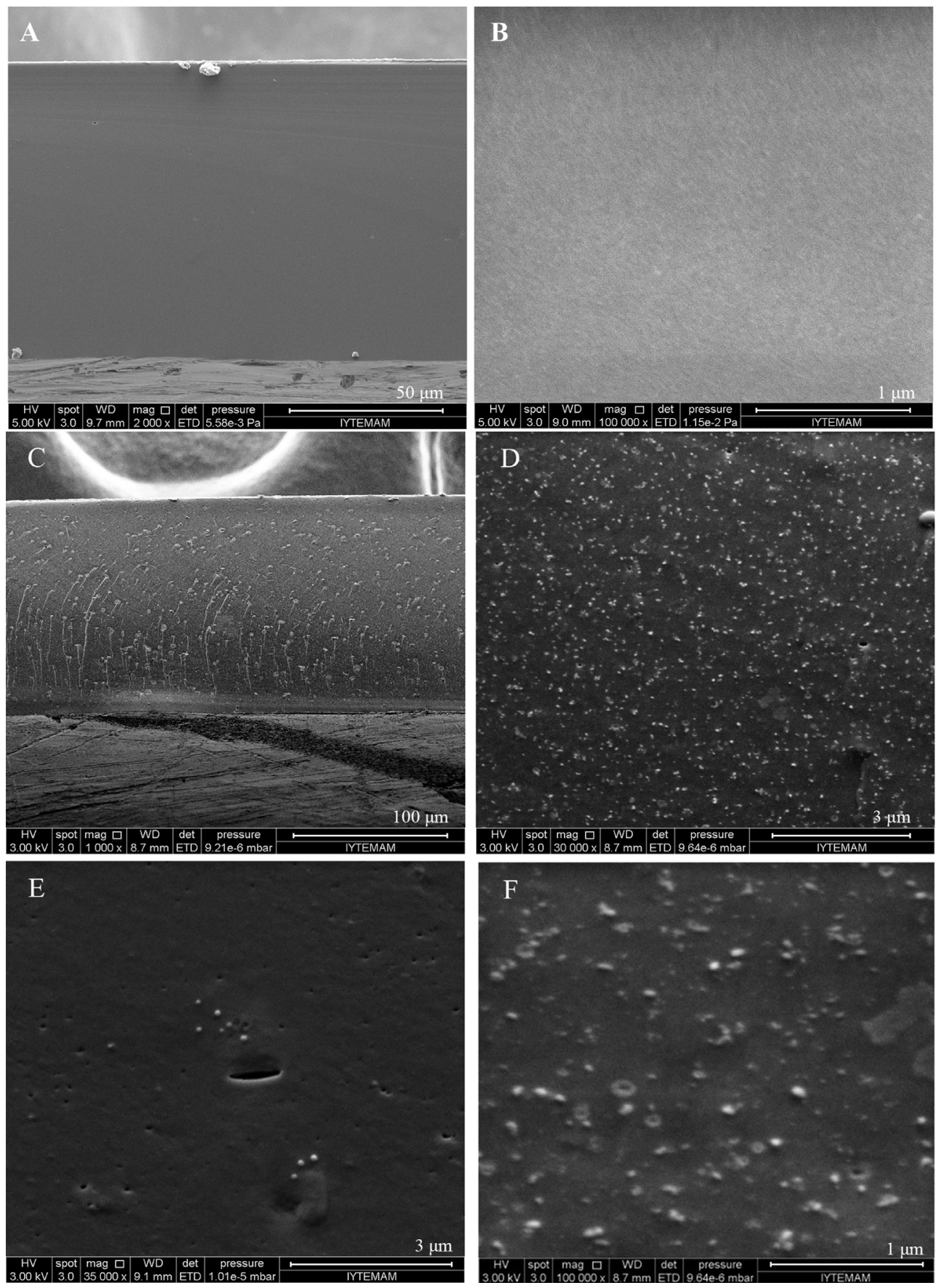

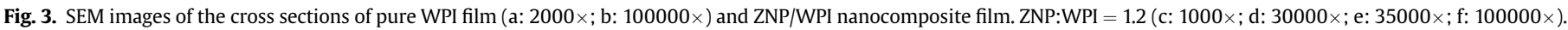

as rigid occupiers of space.

Free volume in a film is a key parameter in determining the chain entanglements and mobility, thus, the properties of a polymer. In 1951, Doolittle (1951) postulated that viscosity should reflect amount of free volume in the polymer and proposed the following relationship between the viscosity and free volume.

$\ln \eta=\ln \mathrm{A}+\mathrm{B}\left(\mathrm{v}-\mathrm{v}_{\mathrm{f}}\right) / \mathrm{v}$

where $\eta$ is the viscosity, $v$ and $v_{f}$ are total volume and fractional free volume of the system, respectively, and A and B are constants (Gabbott, 2008). According to this equation, as the viscosity decreases, fractional free volume increases since the resistance to flow diminishes and consequently the space between the chains increases. To evaluate the changes in the fractional free volume upon nanoparticle addition, we have calculated dynamic viscosity $\left(\eta^{\prime}\right)$ from DMA measurements by dividing loss modulus $\left(G^{\prime \prime}\right)$ by angular frequency (w) (Equation (5))

$\eta^{\prime}=\mathrm{G}^{\prime \prime} / \mathrm{W}$

The results in Fig. 7 show that ZNP filled WPI film exhibited an increase in viscosity relative to the neat polymer, which directly indicates that the fractional free volume in the nanocomposite film was lowered. This result was also supported by the broadened 

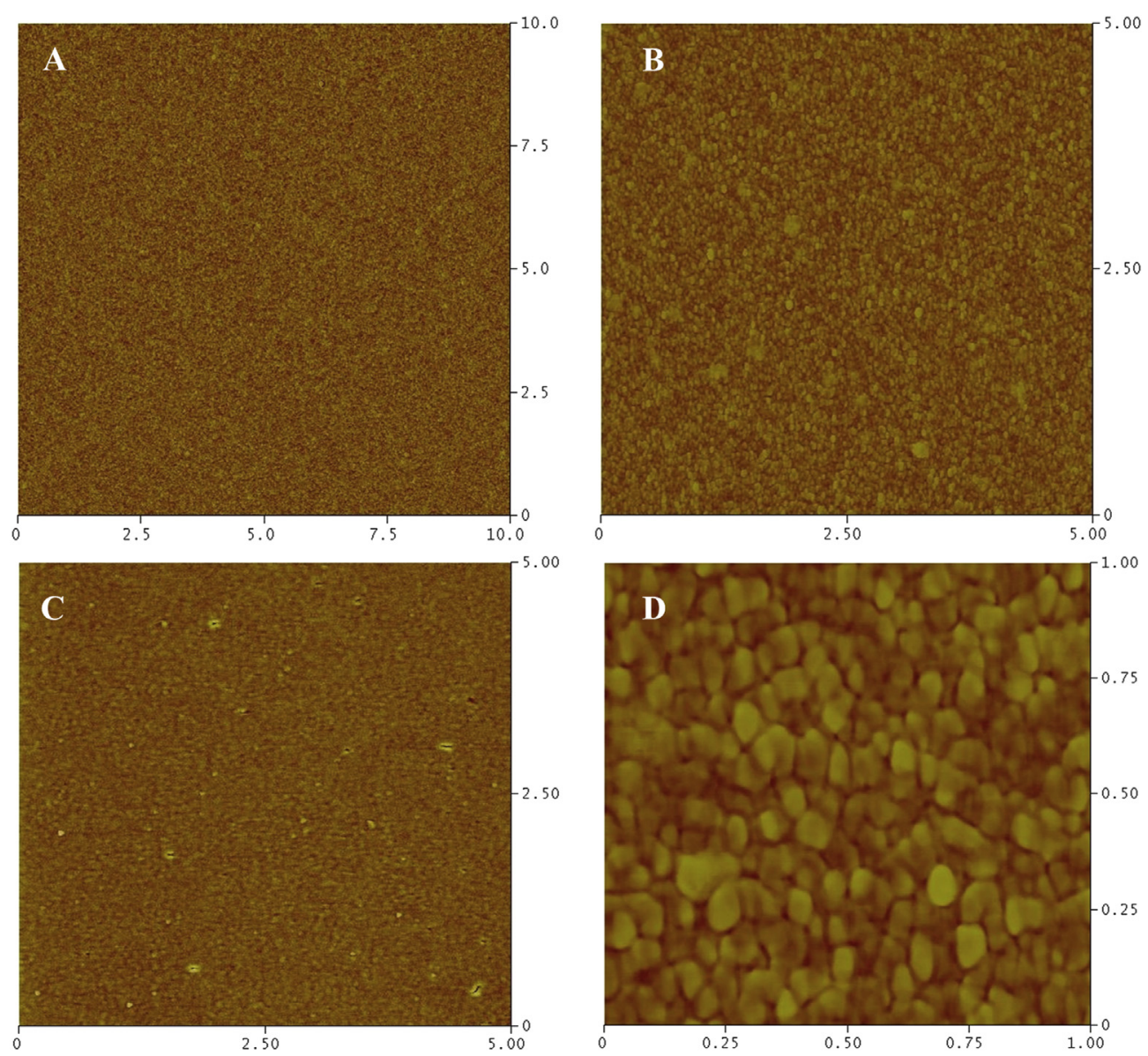

Fig. 4. AFM phase images of pure WPI films (a: $10 \times 10 \mu \mathrm{m}$; b: $5 \times 5 \mu \mathrm{m}$; c: $5 \times 5 \mu \mathrm{m}$; $\mathrm{d}: 1 \times 1 \mu \mathrm{m})$.

transition region in loss modulus as a function of temperature (Fig. 6).

\subsection{Mechanical properties of the films}

Mechanical properties of packaging films are important to maintain their integrity during storage and handling. Tensile strength (TS), elongation at break (E\%) and elastic modulus (EM) are parameters that describe the behavior of film under different circumstances and reveal the changes in microstructure of the film.

The effects of nanoparticle concentration on the tensile strength (TS) and elongation (E\%) of the films are illustrated in Fig. 8. The TS of pure WPI film increased significantly (303\%) from $2.5 \mathrm{MPa}$ to $10.2 \mathrm{MPa}$ by loading ZNP at a ratio of $1.2(\mathrm{w} / \mathrm{w}$ of WPI) into the structure. The reinforcement of ZNP is mainly attributed to an efficient interfacial interaction between them and the matrix, allowing for a good stress transfer. Dispersion of ZNP in the WPI solution is a challenge since zein has an isoelectric point at around 6.2, thus, nanoparticles lose their stability at $\mathrm{pH} 7$ in the film forming solution leading to aggregation. In a previous work, sodium caseinate has been proposed to stabilize colloidal ZNP to increase their application as a carrier for controlled drug delivery or other functional molecules, such as nutraceuticals (Patel, Bouwens, \& Velikov, 2010). Sodium caseinate is an edible protein, which contains hydrophilic and hydrophobic groups in various sequences and proportions, acts as a stabilizer due to the combination of electrostatic and steric stabilization (Patel et al., 2010). The hydrophobic groups of sodium caseinate adsorb on the ZNP while hydrophilic portions provide homogeneous dispersion of the nanoparticle in the hydrophilic WPI matrix. Good dispersion of modified ZNP in the WPI film was previously shown in Figs. 3 and 5 by the morphological characterizations. Furthermore, continuous increase in the tensile strength of the films up to a very high nanoparticle loading level (ZNP:WPI ratio of 1.2) was another evidence for homogeneous distribution of the particles. The zein nanoparticles act not only as reinforcing agent but also as antiplasticizer causing reduction in free volume of the films. Consequently, polymer chains in the nanocomposite films are much more entangled which can support more stress than the plain WPI film. It can be said that the decrease in the free volume of the films upon nanoparticle addition is followed by an improvement in the tensile strength values.

In the case of WPI films as well as other biopolymer based films, the first aim is to improve tensile strength without decreasing elongation values in order to enable the use of WPI as self-standing films rather than as edible coatings. Elongation of the nanocomposite films was comparable to that of the pure WPI film (Fig. 8) except for the lowest loading level (ZNP:WPI ratio of 0.2). The sudden increase in the elongation at this concentration was an indication of the plasticization effect of ZNPs, resulting in increased spacing and mobility between the chains by mitigating the effect of interactions. However, when the nanoparticle concentration was increased, chains were constrained by the nanoparticles and the elongation values were reduced to the level of pure WPI film. Even at the lowest elongation value which was obtained with the highest ZNP:WPI ratio of 1.2 , the value is not significantly smaller than the 

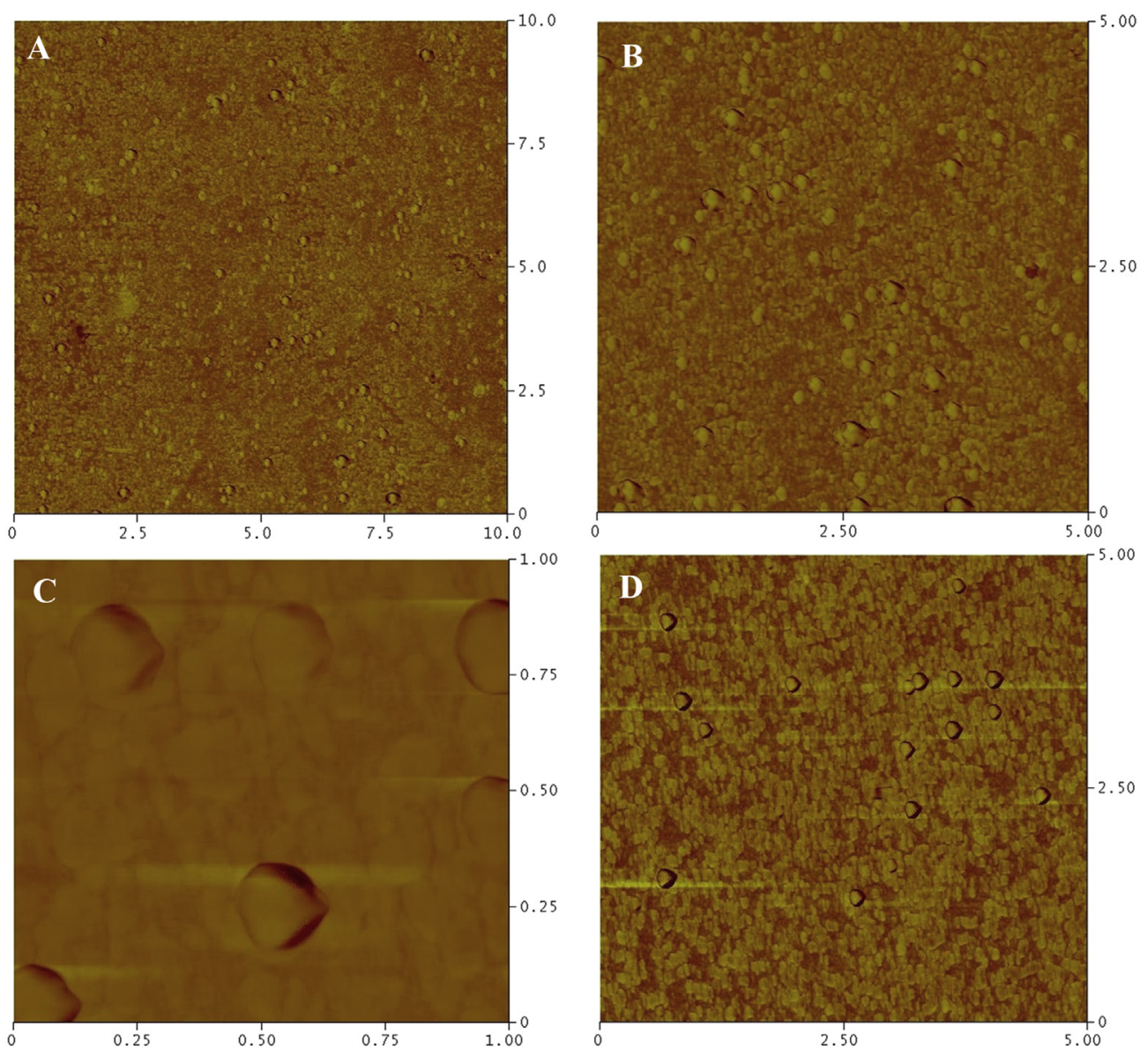

Fig. 5. $A F M$ images of ZNP/WPI nanocomposite film. ZNP:WPI $=1.2(\mathrm{a}: 10 \times 10 \mu \mathrm{m}$; b: $5 \times 5 \mu \mathrm{m}$; c: $1 \times 1 \mu \mathrm{m}$; d: $5 \times 5 \mu \mathrm{m})$.

one in the case of pure WPI film.

In previous studies, WPI based nanocomposite films were prepared with inorganic nanoparticles, $\mathrm{TiO}_{2}$ and clay. Some of these studies reported either no improvement or decrease in mechanical properties upon addition of these nanoparticles (Sothornvit et al., 2009; Zolfi et al., 2014). With the addition of titania, Zhou et al. (2009) and $\mathrm{Li}$ et al. (2011) reached a maximum strength of $2.38 \mathrm{MPa}$ (41\% increment with respect to pure WPI film) and

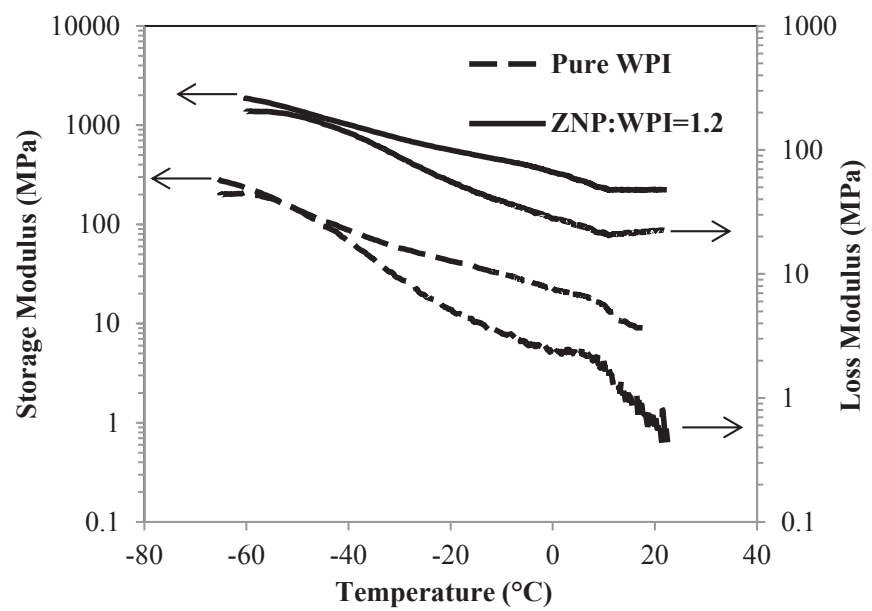

Fig. 6. Storage and loss modulus of pure WPI and ZNP/WPI nanocomposite films $(\mathrm{ZNP}: \mathrm{WPI}=1.2)$.
10.2 MPa (67\% increment), respectively. To achieve a homogeneous distribution of the nanoparticles, Kadam et al. (2013) coated titania with silica, however, they observed only a slight increase in tensile strength from 1.03 to $1.18 \mathrm{MPa}$ (15\% increment). Zolfi et al. (2014), Wakai and Almenar (2015) and Azevedo et al. (2015) measured maximum tensile strengths of $11 \mathrm{MPa}$ (57\% increment with

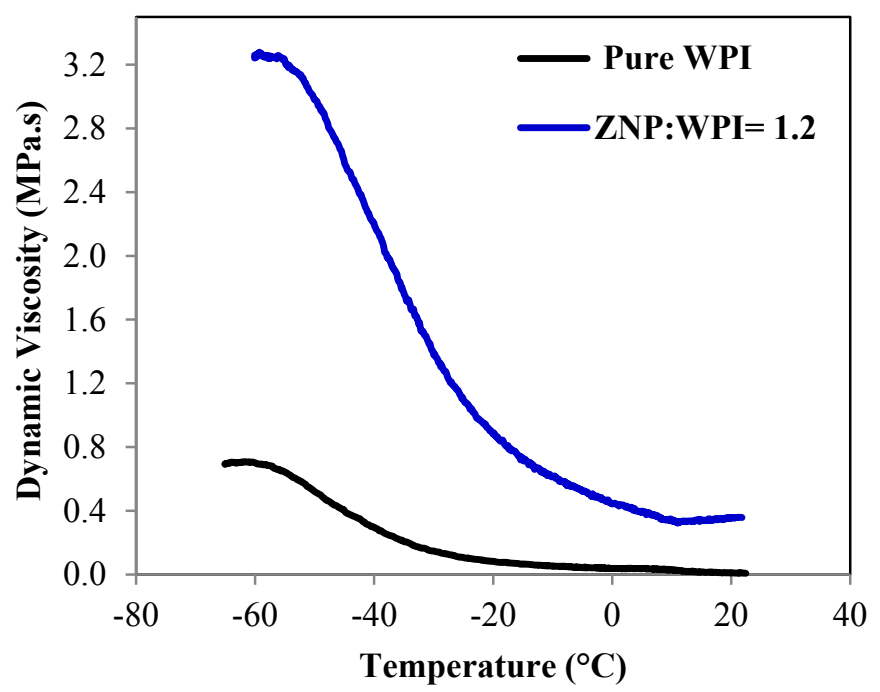

Fig. 7. Comparison of the dynamic viscosities of the pure WPI and ZNP/WPI nanocomposite film (ZNP:WPI = 1.2). 


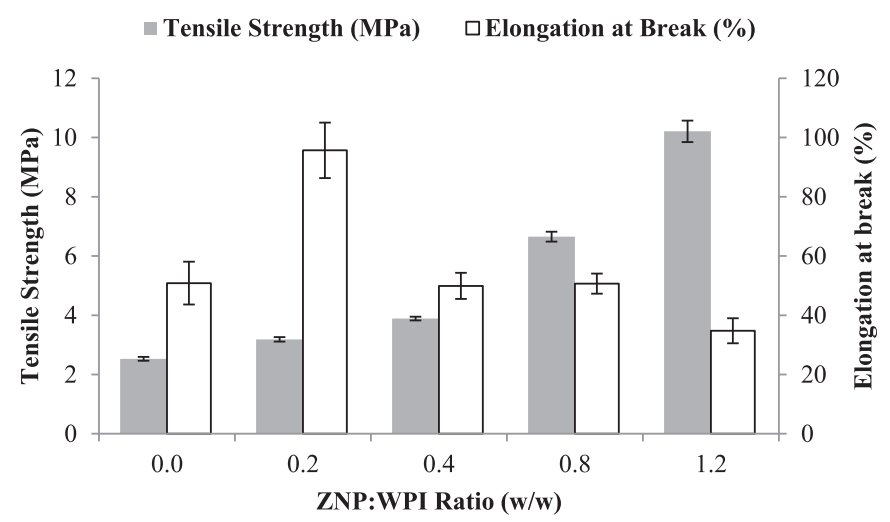

Fig. 8. Tensile strength and elongation values of WPI films as a function of ZNP concentration.

respect to pure WPI film), 2.3 MPa (16\% increment) and $5.42 \mathrm{MPa}$ (49\% increment), respectively. Zein nanoparticle addition caused much higher improvement (303\%) in the maximum strength of the WPI films compared to the $\mathrm{TiO}_{2}$ or clay loading. This is mainly due to the homogeneous dispersion of ZNP in the film and the use of much higher loading levels that cannot be achieved with $\mathrm{TiO}_{2}$ or clay.

\subsection{Water vapor permeability of the films}

Water vapor permeability (WVP) is an important property to determine the feasibility of biodegradable packaging materials made from polymers of agricultural origin. For an accurate evaluation, it is critical to minimize the possibility of swelling of the film during permeation experiments. In the literature, permeation tests were usually performed with a large relative humidity step (0-90\%) where the WPI film swells significantly and the diffusivity of water vapor in the film varies with concentration of water dissolved in the film. Under these conditions, the constant diffusivity and constant film thickness assumptions used in deriving Equation (2) are no longer valid and the WVP calculated from Equation (2) becomes incorrect. In this study, the relative humidity range was set at $25 \%$ during permeation experiments, which did not cause any change in the film thicknesses.

Table 1 shows that the WVP of WPI films decreased gradually as ZNP concentration increased. At the highest loading level (ZNP:WPI ratio of 1.2 ), the decrement was $84 \%$. The change in the permeability can be caused by the kinetic or thermodynamic factor or combination of both since permeability is a product of the diffusivity (kinetic factor) and solubility (thermodynamic factor) of the penetrant. In most of the previous studies, decrease in the permeability of a penetrant through a nanocomposite film was explained by an extended diffusive trajectory since the penetrant molecules can only travel around the particles. Although this is a valid reason, other factors can also influence the structure of the

Table 1

WVP of WPI films as a function of ZNP concentration.

\begin{tabular}{lll}
\hline $\begin{array}{l}\text { ZNP:WPI } \\
\text { ratio }(\mathrm{w} / \mathrm{w})\end{array}$ & $\begin{array}{l}\text { Average } \\
\text { thickness }(\mu \mathrm{m})\end{array}$ & $\begin{array}{l}\text { Water vapor } \\
\text { permeability } \\
\left(\mathrm{g} \mathrm{mm} / \mathrm{m}^{2} \mathrm{~h} \mathrm{kPa}\right)\end{array}$ \\
\hline 0.0 & 71 & $0.322 \pm 0.009$ \\
0.2 & 98 & $0.176 \pm 0.014$ \\
0.4 & 107 & $0.123 \pm 0.012$ \\
0.8 & 131 & $0.086 \pm 0.007$ \\
1.2 & 151 & $0.052 \pm 0.002$ \\
\hline
\end{tabular}

films and, consequently change their water-vapor barrier efficiency. We have shown that the interaction between the nanoparticles and the polymer decreased the chain mobility and free volume (Fig. 7) allowing for lower diffusion rates, consequently, improved water barrier efficiency of the ZNP/WPI nanocomposite films. Another reason for the reduction in the water vapor permeability with nanoparticle addition is the hydrophobic nature of ZNP which act as moisture transfer barriers. This was proven by the lower rate of absorption of water into the nanocomposite film compared to that into the plain WPI film.

Several previous studies focused on improving the water vapor barrier properties of the WPI films. Zhou et al. (2009) used $4 \% \mathrm{TiO}_{2}$ and observed a 70\% decrease in WVP while Zolfi et al. (2014) and Li et al. (2011) observed 14\% and 9.4\% decreases by adding 5\% and 1\% $\mathrm{TiO}_{2}$, respectively. Kadam et al. (2013) and Sothornvit et al. (2009) did not obtain any gain in the barrier property of the WPI film after adding silica coated $\mathrm{TiO}_{2}$ and clay nanoparticles, respectively. Zolfi et al. (2014) reported that WVP decreased by $57 \%$ with $5 \%$ clay addition while Sothornvit, et. al. (2010) observed 41\% decrease upon $20 \%$ clay addition into WPI films. When compared with these previous data, we found that ZNP addition allows for a better improvement of the water vapor barrier properties of the WPI films. This can be attributed to two factors: 1) Zein is much more hydrophobic than $\mathrm{TiO}_{2}$ and clay as confirmed by lower contact angle values of zein (Yoshino, Isobe, \& Maekawa, 2000) compared to clay (Prakash, 2004) and $\mathrm{TiO}_{2}$ (Stevens, Priest, Sedev, \& Ralston, 2003). The hydrophilic materials attract water, increasing the solubility of water vapor and enhancing the permeability. 2) Zein can be distributed homogeneously through the WPI film (Fig. 5) and can be loaded at a much higher concentration than $\mathrm{TiO}_{2}$ and clay without changing the mechanical integrity of the film (Fig. 8). Dispersion of the nanoparticles in the matrix is a critical determinant for the barrier properties. Homogeneous dispersion of inorganic nanoparticles, such as $\mathrm{TiO}_{2}$ and clay in a polymeric matrix cannot be easily achieved even with a compatibilizer. The discontinuity in the nanocomposite films due to agglomeration of the nanoparticles would have an adverse effect on the barrier properties. These hypotheses were supported by several studies showing that hydrophilic and heterogeneous materials had a higher moisture vapor transmission rate (Debeaufort, Martinpolo, \& Voilley, 1993; Debeaufort, Quezada-Gallo, Delporte, \& Voilley, 2000).

\section{Conclusion}

The water vapor barrier and mechanical properties of WPIbased films were improved by blending with ZNP. Improvement in the barrier property is mainly due to hydrophobic nature of ZNP, hence, the decrease in the solubility of water vapor in the film. In addition, the decline in the fractional free volume of the films in the presence of nanoparticles results in restricted mobility of the polymer chains allowing for a lower diffusion rate of water vapor through the film. Homogeneous distribution of nanoparticles in the films achieved by modifying the particles with sodium caseinate enables high loading levels and good stress transfer, and as a result, leads to the significant reinforcement and enhanced barrier property of the films.

The nanoparticles extend the diffusive trajectory in the film, hence, permeation of the water vapor molecules slows down. On the other hand, this argument based on purely geometrical effect is not adequate to explain the improvement in the water vapor barrier properties of the films. We have shown that both kinetic and thermodynamic factors play a role in the decreased water vapor permeabilites, therefore, one should take into account both factors in the design of a nanocomposite film. To the best of our knowledge, this is the first study which reported the use of zein nanoparticles 
in WPI films for improving its mechanical and water vapor barrier properties. Our results suggest that ZNP/WPI nanocomposite films have the great potential to be used as biodegradable food packaging materials.

\section{Acknowledgments}

We acknowledge Izmir Institute of Technology Biotechnology and Bioengineering and Material Research Centers for their technical support.

\section{References}

ASTM F1249-90. (1995). Standard test method for water vapor transmission rate through plastic film and sheeting using a modulated infrared sensor. ASTM International, pp. 1-5.

ASTM D882-02. (2002). Standard test method for tensile properties of thin plastic sheeting, ASTM International, pp. 1-9.

Azevedo, V. M., Dias, M. V., Borges, S. V., Ana Letícia, R., Costa, A. L. R., Silva, E. K. et al. (2015). Development of whey protein isolate bio-nanocomposites: effect of montmorillonite and citric acid on structural, thermal, morphological and mechanical properties. Food Hydrocolloids, 48, 179-188.

Brindle, L. P., \& Krochta, J. M. (2008). Physical properties of whey proteinhydroxypropylmethylcellulose blend edible films. Journal of Food Science, 73, E446-E454.

Debeaufort, F., Martinpolo, M., \& Voilley, A. (1993). Polarity homogeneity and structure affect water-vapor permeability of model edible films. Journal of Food Science, 58, 426-429.

Debeaufort, F., Quezada-Gallo, J. A., Delporte, B., \& Voilley, A. (2000). Lipid hydrophobicity and physical state effects on the properties of bilayer edible films. Journal of Membrane Science, 180, 47-55.

Doolittle, A. K. (1951). Studies in Newtonian flow. II. The dependence of the viscosity of liquids on free-space. Journal of Applied Physics, 22, 1471-1475.

Fairley, P., Monahan, F. J., German, J. B., \& Krochta, J. M. (1996). Mechanical properties and water vapor permeability of edible films from whey protein isolate and sodium dodecyl sulfate. Journal of Agricultural and Food Chemistry, 44, $438-443$.

Fang, Y., Tung, M. A., Britt, I. J., Yada, S., \& Dalgleish, D. G. (2002). Tensile and barrier properties of edible films made from whey proteins. Journal of Food Science, 67, $188-193$.

Ferry, J. D. (1980). Viscoelastic properties of polymers (3 ed.). New York: John Wiley\&Sons (Chapter 1).

Gabbott, P. (2008). Principles and applications of thermal analysis. In J. Duncan (Ed.), Principles and applications of mechanical thermal analysis (pp. 119-163). Oxford: Blackwell Publishing Ltd.

Gounga, M. E., Xu, S. Y., \& Wang, Z. (2007). Whey protein isolate-based edible films as affected by protein concentration, glycerol ratio and pullulan addition in film formation. Journal of Food Engineering, 83, 521-530.

Hong, S. I., \& Krochta, J. M. (2003). Oxygen barrier properties of whey protein isolate coatings on polypropylene films. Journal of Food Science, 68, 224-228.

Ikeda, S., \& Morris, V. J. (2002). Fine-stranded and particulate aggregates of heatdenatured whey proteins visualized by atomic force microscopy. Biomacromolecules, 3, 382-389.

Kadam, D. M., Thunga, M., Wang, S., Kessler, M. R., Grewell, D., Lamsal, B., et al. (2013). Preparation and characterization of whey protein isolate films reinforced with porous silica coated titania nanoparticles. Journal of Food Engineering, 117, 133-140.

Karbowiak, T., Debeaufort, F., \& Voilley, A. (2006). Importance of surface tension characterization for food, pharmaceutical and packaging products: a review.
Critical Reviews in Food Science and Nutrition, 46, 391-407.

Khwaldia, K., Perez, C., Banon, S., Desobry, S., \& Hardy, J. (2004). Milk proteins for edible films and coatings. Critical Reviews in Food Science and Nutrition, 44, 239-251.

Kingery, W. D., Bowen, H. K., \& Uhlmann, D. R. (1960). Introduction to ceramics (2nd ed.). New York: John Wiley \& Sons.

Kokoszka, S., Debeaufort, F., Lenart, A., \& Voilley, A. (2010b). Water vapour permeability, thermal and wetting properties of whey protein isolate based edible films. International Dairy Journal, 20, 53-60.

Li, Y. X., Jiang, Y. F., Liu, F., Ren, F. Z., Zhao, G. H., \& Leng, X. J. (2011). Fabrication and characterization of $\mathrm{TiO}_{2}$ /whey protein isolate nanocomposite film. Food $\mathrm{Hy}$ drocolloids, 25, 1098-1104.

Li, K. K., Yin, S. W., Yin, Y. C., Tang, C. H., Yang, X. Q., \& Wen, S. H. (2013). Preparation of water-soluble antimicrobial zein nanoparticles by a modified antisolvent approach and their characterization. Journal of Food Engineering, 119, 343-352.

Mchugh, T. H., Aujard, J. F., \& Krochta, J. M. (1994). Plasticized whey-protein edible films - water-vapor permeability properties. Journal of Food Science, 59, 416-419.

Mchugh, T. H., \& Krochta, J. M. (1994). Water-vapor permeability properties of edible whey protein-lipid emulsion films. Journal of the American Oil Chemists Society, 71, 307-312.

Min, S. C., Janjarasskul, T., \& Krochta, J. M. (2009). Tensile and moisture barrier properties of whey protein-beeswax layered composite films. Journal of the Science of Food and Agriculture, 89, 251-257.

Patel, A. R., Bouwens, E. C. M., \& Velikov, K. P. (2010). Sodium caseinate stabilized zein colloidal particles. Journal of Agricultural and Food Chemistry, 58 12497-12503.

Perez-Gago, M. B., Serra, M., Alonso, M., Mateos, M., \& del Rio, M. A. (2005). Effect of whey protein- and hydroxypropyl methylcellulose-based edible composite coatings on color change of fresh-cut apples. Postharvest Biology and Technology, 36, 77-85.

Prakash, B. S. J. (2004). Surface thermodynamics of clay. In F. Wypych, \& K. G. Satyanarayana (Eds.), Clay surfaces: Fundamentals and applications (pp. 93-94). Elsevier Inc.

Riddick, T. M. (1968). Zeta-meter manual. New York: Zeta.

Sothornvit, R., Hong, S. I., An, D. J., \& Rhim, J. W. (2010). Effect of clay content on the physical and antimicrobial properties of whey protein isolate/organo-clay composite films. LWT-Food Science and Technology, 43, 279-284.

Sothornvit, R., \& Krochta, J. M. (2000). Oxygen permeability and mechanical properties of films from hydrolyzed whey protein. Journal of Agricultural and Food Chemistry, 48, 3913-3916.

Sothornvit, R., Rhim, J. W., \& Hong, S. I. (2009). Effect of nano-clay type on the physical and antimicrobial properties of whey protein isolate/clay composite films. Journal of Food Engineering, 91, 468-473.

Stevens, N., Priest, C. I., Sedev, R., \& Ralston, J. (2003). Wettability of photoresponsive titanium dioxide surfaces. Langmuir, 19, 3272-3275.

Wakai, M., \& Almenar, E. (2015). Effect of the presence of montmorillonite on the solubility of whey protein isolate films in food model systems with different compositions and pH. Food Hydrocolloids, 43, 612-621.

Wihodo, M., \& Moraru, C. I. (2013). Physical and chemical methods used to enhance the structure and mechanical properties of protein films: a review. Journal of Food Engineering, 114, 292-302.

Yoshino, T., Isobe, S., \& Maekawa, T. (2000). Physical evaluation of pure zein films by atomic force microscopy and thermal mechanical analysis. Journal of the American Oil Chemists' Society, 77, 699-704.

Zhou, J. J., Wang, S. Y., \& Gunasekaran, S. (2009). Preparation and characterization of whey protein film incorporated with $\mathrm{TiO}_{2}$ nanoparticles. Journal of Food Science, 74. N50-N56.

Zolfi, M., Khodaiyan, F., Mousavi, M., \& Hashemi, M. (2014). The improvement of characteristics of biodegradable films made from kefiran-whey protein by nanoparticle incorporation. Carbohydrate Polymers, 109, 118-125. 